\title{
مقارنة بين خزانات التموج المستخدمة في الحماية من مشكلة مطرقة الماء في المحطات الكهرومائية
}

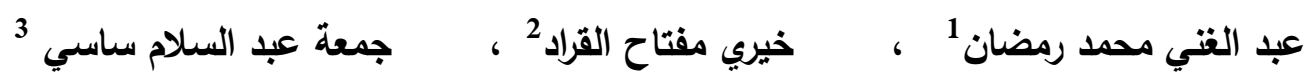
2،1 2، فسم الهندسة اليكانيكية، كلية الهنسة، القزه بوللي

3 قسم الهنسة الكيميائية، كلية الهندسة، القره بوللي الئية

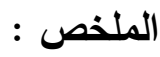

تم في هذا البحث إجراء مقارنة بين نوعين من خزانات التموج المستخدمة في الحمايـة من مشكلة مطرقة الماء في الدحطات الكهرومائية وهما الخزان البسيط ، و الخزان ذو الفتحة. وقد استخدم

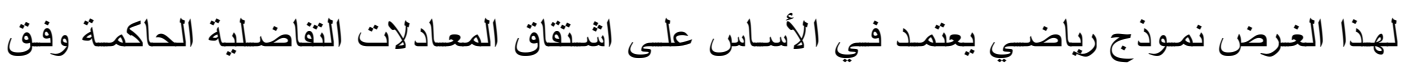

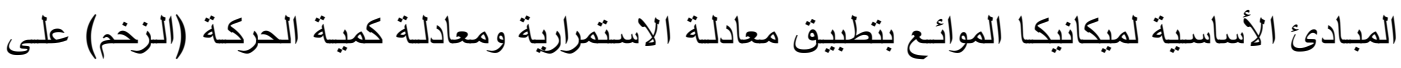
الخزانين، وحله باستخدام الطرق العددية وبالاستعانة ببرامج الحاسب الآلي تحت الثروط الابتدائية

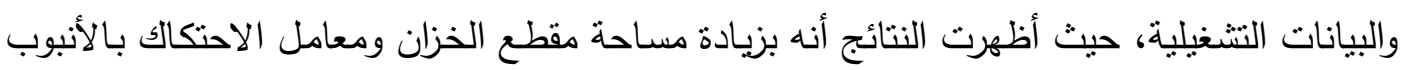
الرئيس انخفض مستوى الاندفاع المفاجئ الأول في الخزان ، وكذللك معدلات التصريف سواء في بـ

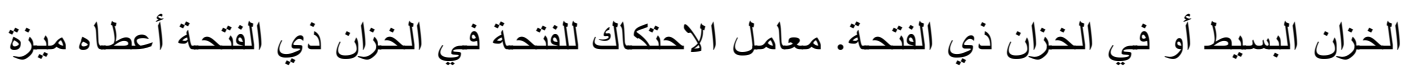
إضافية على الخزان البسيط، فمن خلال المقارنة بين النتائج للخزانين اتضح أن الخزان ذا الفتحة هو أفضل استخداما من الخزان البسيط في المحطات الكهرومائية، وذلك ناتج عن التأثير الإيجابي للفتحة في إخماد مستوى الاندفاعات المفاجئة والتقليل من التذبذبات والتقلبات و تقليل زمن التخميد ومعدلات التصريف.

الكلمات المفتاحية : المطرقة المائية- الخزان البسيط- الخزان ذو الفوهة- الاندفاع المفاجئ.

مقدمة

تعد ظاهرة الموجة المصاحبة للتغير المفاجئ في سرعة المائع في الأنبوب من أخطر المشاكل التي تواجه خطوط الأنابيب، حيث يطلق مصطلح " المطرقة المائية" على الضغط العابر الذي يؤثر بشكل

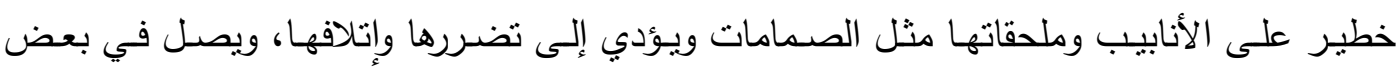


الأحيان إلى تعريض حياة العاملين للخطر ، وما يترتب على ذلك من خسائر اقتصسادية وتأثيرات

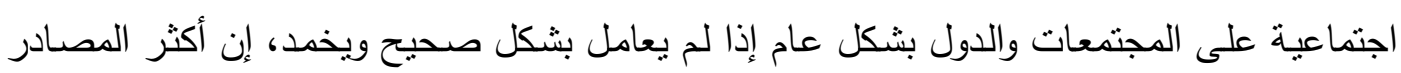
شيوعا للضغوط العابرة هي تلك المتعلقة بالتغير المفاجئ في الطلب على التوربين في المحطات الكهرومائية ، أو أثناء الققل الجزئي أو الكلي لصمامات التحكم، أو أثناء الأعطال والتوقفات الدفاجئة في المضخات أو التربينات العاملة على خطوط الأنابيب. توجد عدة طرق للتحكم والسيطرة على هذه الظاهرة والتقليل من تأثيرها السلبي من بينها استخدام خزانات التموج أو خزانات كبح الاندفاع المفاجئ، الثكل (1) يوضح خزان تموج بسيط مربوط مع خط الأنابيب بعد الخزان الرئيس وقبل التربينة. تتلخص وظيفة خزان التموج بشكل عام في: (أ) تخميد وكبح موجة الاندفاع المفاجئ الناتجة عن التقلبات في الضغط .(ب) يعمل خزان التموج على تحسين وتنظيم عمل التربينات الهيدروليكية.(ج) يخزن المياه ويعطيها وقت الحاجة وذلك عن طريق تعجيل أو تأخير سريان المياه داخل خط الأنابيب.

توجد أنواع عدة من خزانات كبح الاندفاع الدفاجئ (التموج) نذكر منها: الخزان البسيط ، والخزان ذا الفتحة، والخزان التفاضلي، والخزان ذا الاتجاه الواحد، والخزان المغلق (المقفل)، و الخزان ذا الدهاليز (الأروقة). حازت مشكلة مطرقة الماء على اهتمام كبير وواسع من قبل الباحثين والمختصين في هذا

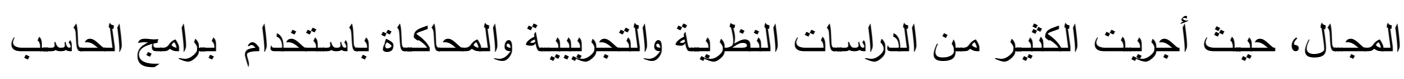
الآلي تحت الظروف التشغيلية المختلفة، لاستخلاص النتائج ومناقثتها والخروج باستتناجات وتوصيات

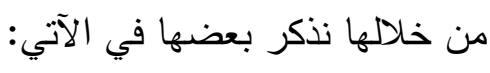

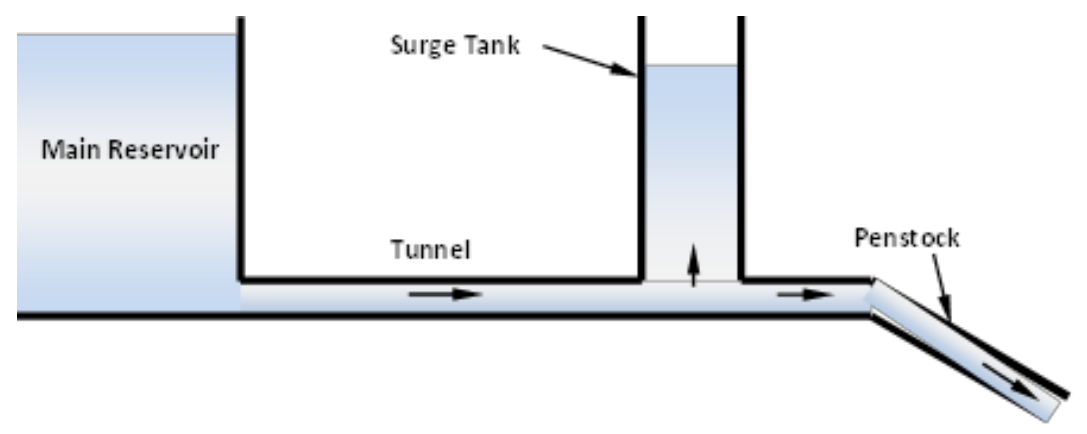

الثكل (1) : رسم تخطيطي لخزان كبح الاندفاع المفاجئ (التموج). 
في دراسـة سـابقة (Ramadan A.M \& Mustafa .H (2013) قام المؤلفون بدراسـة الاعتبارات التصميمية لخزانات التموج للتحكم في مشكلة مطرقة الماء في المحطات الكهرومائية، وتم التركيز بشكل خاص على إجراء دراسـة نظريـة على خزان التموج البسيط لمعرفة تأثنير العوامل التصميمية والمتغيرات المختلفة على المشكلة، ثم إيجاد ارتفاع الموجة ومعدل التصريف وتأثنير معامل الاحتكالك في نطاق بيانات تشغيلية مختلفة كدالة في الزمن للحصول على أفضل قيم تصميمية تلائم المحطة الكهرومائية المقترحة.

غلام وآخرون (Ghulam N., et al. (2011) أجروا دراسة على استخدام بعض أنواع خزانات التموج في محطتين من المحطات الكهرومائية في باكستان هما : محطة ساتبارا ، ومحطة قولون قل، هذه الأنواع هي خزان التموج من غير غرفة، خزان التموج بغرفتين ، و خزان التموج بغرفة ، وذلك بحساب ارتفاع الموجة والزمن اللزم لإخمادها، حيث تم دراستها في ظروف تشغيل مختلفة: في حالة قفل تام، وفي حالة فتح تام.

خلصت هذه الدراسـة الى أن خزان التموج بغرفة واحدة في محطـة سـاتبارا، كان الأفضل في إخمـاد الموجة واستقرارها من النوعين الآخرين، بينما في محطة قولون قل، كان خزان التموج بغرفنين أفضل من النوعين الآخرين في تخميد موجة الاندفاع المفاجئ.

ازهري موهادام (Azhdary M. (2004) في هذه الدراسـة تم اشتقاق المعادلات التفاضلية الحاكمـة لحساب أقصسى ارتفاع للموجـة وأقل ارتفاع لها ، والتذبدبات التي تحدث في خزان التموج بعد إجراء تعديل في الحد الخاص بالاحتكاك، حيث إن حد الاحتكالك عادة مايكون غير خطي، لهذا تم إيجاد الحل العام لهذه المعادلات باستخدام التحليلات اللابعدية.

فورهيفن وآخرون(Verhoeven R., et al (1998) أجروا دراسـة مقارنة لبعض الأنواع التجارية من الحجرات الهوائية المستخدمة في تخميد الموجة في خطوط الأنابيب المضغوطة، منها حجرة الهواء الكلاسيكية، والنوع الكلاسيكي المجهز ببالون مطاطي، والنوع الكلاسيكي المزود بوصلتين، وأخيرا النوع الحديث من الحجرات الهواية المعزولة. تم التعرض للمبادئ الأساسية في تشغيلها تحت الظروف المختلفـة، ومعرفـة أمساكن تطبيقها، وذلك من خـلا أمنلـة تجريبيـة في مجال تطبيقات كل نوع من أنواعها. 
خلصت الدراسة الى أن الحجرات الهوائية الكلاسيكية كانت الأفضل في تخميد الموجة والتحكم فيها

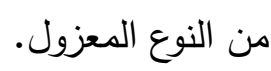

بينار بربراوغلو (Pinar B. B (2013) أجرت دراسـة نظريـة لتحديد أبعاد خزانات التموج الفعالة في

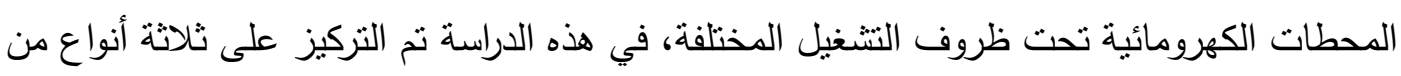
خزانات التموج: الخزان البسيط ، الخزان ذو الفتحة ، والخزان ذو العمود. اعتمدت الدراسة على اشتتقاق المعادلات الثفاضلبة الحاكمة في مشكلة مطرقة الماء وحلها، بالإضافة إلى تحجيم الخزانات بواسطة اشتقاق علاقات تجريبية بواسطة التحليلات اللابعدية، وإجراء دراسة اقتصادية عليها.

اربانوفيتش وآخرون (Urbanowicz K., et al (2016) أجروا دراسة حول مشكلة المطرقة المائية في أنابيب البوليمر المرنة، وذلك بتقديم وتحليل نموذج رياضي جديد، حيث تم إضافة حد جديد لمعادلة الاستمرارية لوصف التشوه المتأخر في أنابيب البوليمر، السلوك الميكانيكي تم وصفه باستخدام نموذج ونج

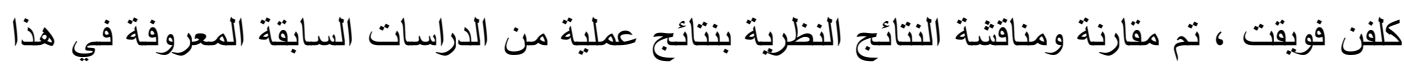
المجال.

في هذه الورقة سيتم دراسة مشكلة مطرقة الماء نظرياً لمعرقة تأثير المتغيرات المختلفة، وإجراء مقارنة بين خزان التموج البسيط والخزان ذو الفتحة في تخميد الموجة والتقليل من زمن التخميد، وذلك بحساب

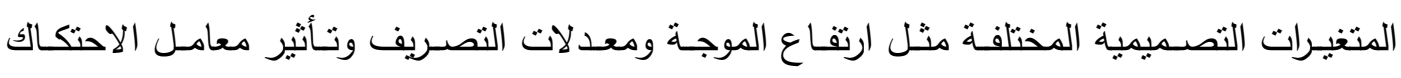

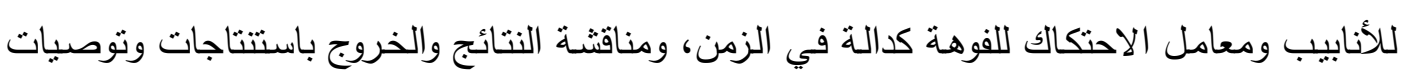
بشأنها. النموذج الرياضي

تم في هذه الدراسة الاعتماد على النموذج الرياضي المستخدم في العديد من المراجع، وكمثال على ذلك ( Pinar B. (2013) ، (Chaudhry M.H. (1987)، وتم اشتقاق المعادلات التفاضلية العادية الحاكمة، بتطبيق معادلـة الاستمرارية ومعادلـة كميـة الحركة (الزخم)، على عنصر (جزء) تفاضلي

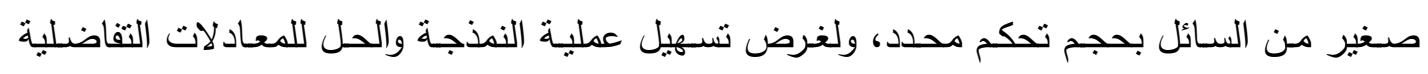
العادية الحاكمة، تم إجراء بعض الافتراضات الثالية:

i - جدران الأنبوب الرئيس (القناة المائية) غير مرنة ، والسائل (الماء) غير قابل للانضغاط. 
-ii القصور الذاتي للسائل (الماء) في خزان التموج صغير جداً عند مقارنته بالقصور الذاتي للماء داخل القناة الرئيسية، ولهذا يمكن إهماله.

- الفقد في الضغط يمكن حسابه باستخدام معادلات الحالة المستقرة لسرعات السريان المناظرة.

\section{الذزان البسيط}

في الخزان البسيط الموضح بالثكل (2-أ)، يكون الخزان مربوط مباشرة في العادة على خط الأنابيب بين الخزان الرئيس (السد)، والتربينة.

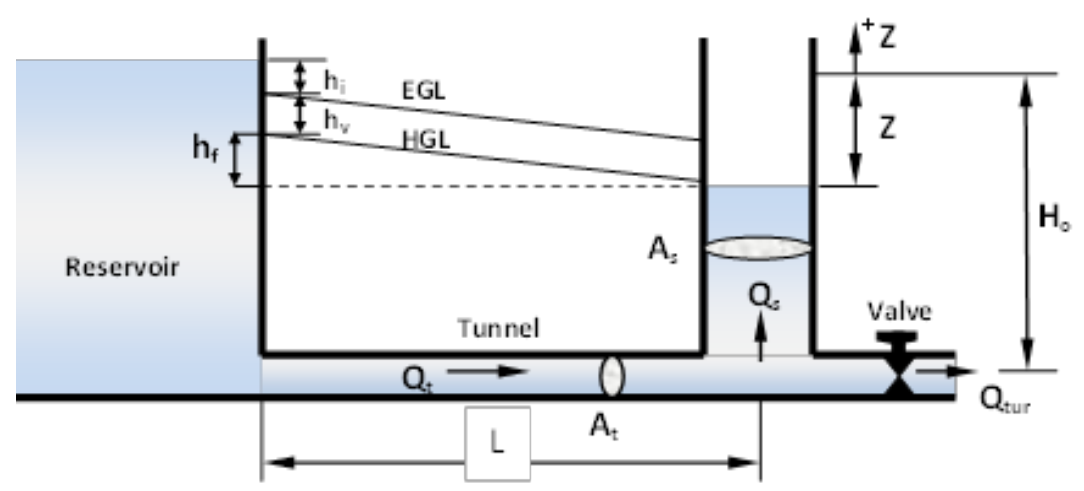

الثكل (2-) (أ): خزان التموج البسيط

المعادلات التفاضلية العادية الحاكمة الناتجة عن تطبيق معادلة كمية الحركة (الزخم)، معادلة (1)، ومعادلة الاستمرارية ، معادلة (2)، هي:

$$
\begin{aligned}
& (1) \ldots \ldots \ldots \ldots \ldots \ldots \frac{\mathbf{d Q}_{\mathbf{t}}}{\mathbf{d t}}=\frac{\mathbf{g A}_{\mathbf{t}}}{\mathbf{L}}\left(-\mathbf{Z}-\mathbf{C Q}_{\mathbf{t}}\left|\mathbf{Q}_{\mathbf{t}}\right|\right) \\
& (2) \ldots \ldots \ldots \ldots \ldots \ldots \ldots \ldots) \frac{\mathbf{d Z}}{\mathbf{d t}}=\frac{1}{\mathbf{A}_{\mathrm{s}}}\left(\mathbf{Q}_{\mathbf{t}}-\mathbf{Q}_{\text {tur }}\right)
\end{aligned}
$$

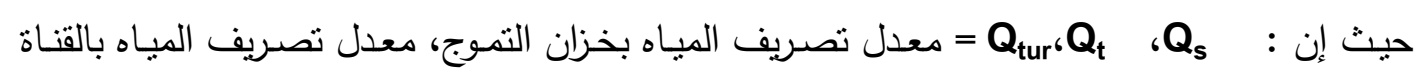
الرئيسية، معدل تصريف المياة للتربينة (kg/s).

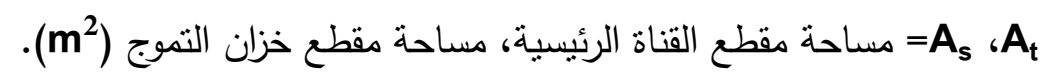




$$
\begin{aligned}
& \text { = معامل الاحتكالك لجدار القناة الرئبسبة. C } \\
& \text { Z Z Z Zستوى المياه بخزان التموج (m). } \\
& \text { g }=
\end{aligned}
$$

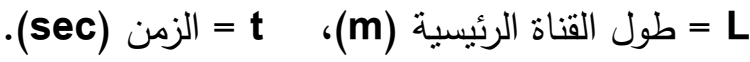

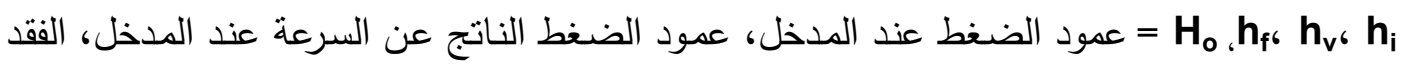
في الضغط نتيجة الاحتكالك وعمود الضغط الاستاتيكي (m)،على التوالي.

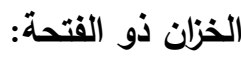
في الخزان ذو الفتحـة، توجد فتحـة، تعيق حركة السـائل من وإلى خزان التمـوج، موجودة بين القناة الرئيسية للماء وخزان التموج، كما هو موضح بالثكل (2-ب).

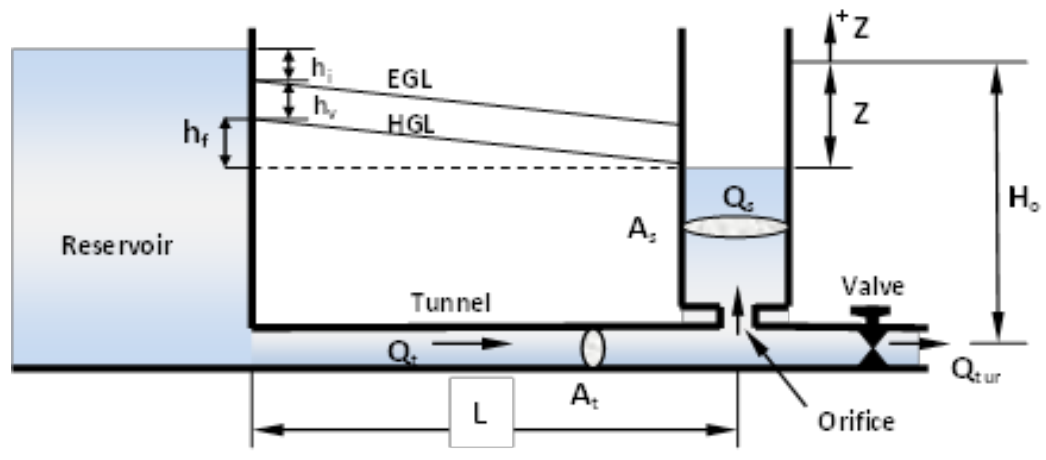

الثكل (2-ب): خزان التموج ذو الفتحة.

المعادلات التفاضلية العادية الحاكمة الناتجة عن تطبيق معادلة كمية الحركة (الزخم)، معادلة (3)، ومعادلة الاستمرارية ، معادلة (4)، هي:

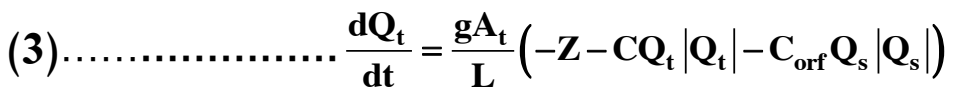

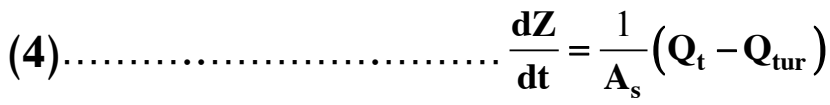

حيث إن: C Corf = معامل الاحتكاك للفتحة اسفل خزان التموج. 


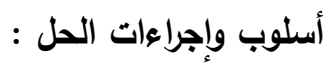

إن أسلوب وإجراءات الحل يعتمد بالأساس على حل منظومة المعادلات التفاضلية العادية عدديا وآنيا، وفق الثروط الابتدائية والبيانات التشغيلية المبينة بالجدول (1)، باستخدام طريقة رانج كوتا بالاستعانة ببرنامج الحاسب الآلي (MATLAB)، في حل هذه المعدلات.

جدول رقم(1): الثروط الابتدائية والبيانات التشغيلية لمحطة كهرومائية افتراضية.

\begin{tabular}{|c|c|c|c|}
\hline الوحدات & القيمة & الرمز & ر.J \\
\hline$(m)$ & 500 & L & -1 \\
\hline$(\mathrm{m})$ & 0.0 & $Z(0)$ & -2 \\
\hline$\left(\mathrm{m}^{3} / \mathrm{s}\right)$ & 300 & $Q_{\mathrm{t}}(0)$ & -3 \\
\hline$\left(m^{3} / s\right)$ & 0.0 & $Q_{\text {tur }}$ & -4 \\
\hline$\left(m^{2}\right)$ & 80 & $A_{t}$ & -5 \\
\hline$\left(m^{2}\right)$ & 100 & $A_{s}(0)$ & -6 \\
\hline & 0.0 & $\mathrm{C}(0)$ & -7 \\
\hline & 0.1 & $\mathrm{C}_{\text {orf }}(0)$ & -8 \\
\hline (sec) & 0.5 & $\Delta \mathrm{t}$ & -9 \\
\hline
\end{tabular}

\section{النتائج والمناقشة}

الخزان البسيط. تأثير تغيير مساحة مقطع الذزان على مستوي الماء في الخزان: في الثكل (3) نم توضيح تأثير تغيير مساحة مقطع الخزان على مستوي الماء في الخزان حيث من الواضـح أنـه إذا زادت مسـاحة مقطع الخزان انخفض مستوى الاندفاع المفاجئ للمـاء خلالهه ، أي أن هناك تتاسبا عكسيا بينهما وذلك لأن زيادة مساحه مقطع الخزان عند ثبوت كمية الماء فيه يؤدي إلى انخفاض مستوى الماء داخله، ومن خلال الثكل، يمكن ملاحظة أن مستوى الاندفاع المفاجئ في المرحلة الاولى ينخفض من 7 متز، عند مساحه مقطع 200 (م²) إلي حوالي 3 متر عند مساحه 
مقطع 600 (2²). كمـا يتضـح مـن خـلا الثـكل أن الزمن الـلازم لتخميد الموجـة يقل كلمـا زادت مساحة مقطع الخزان.

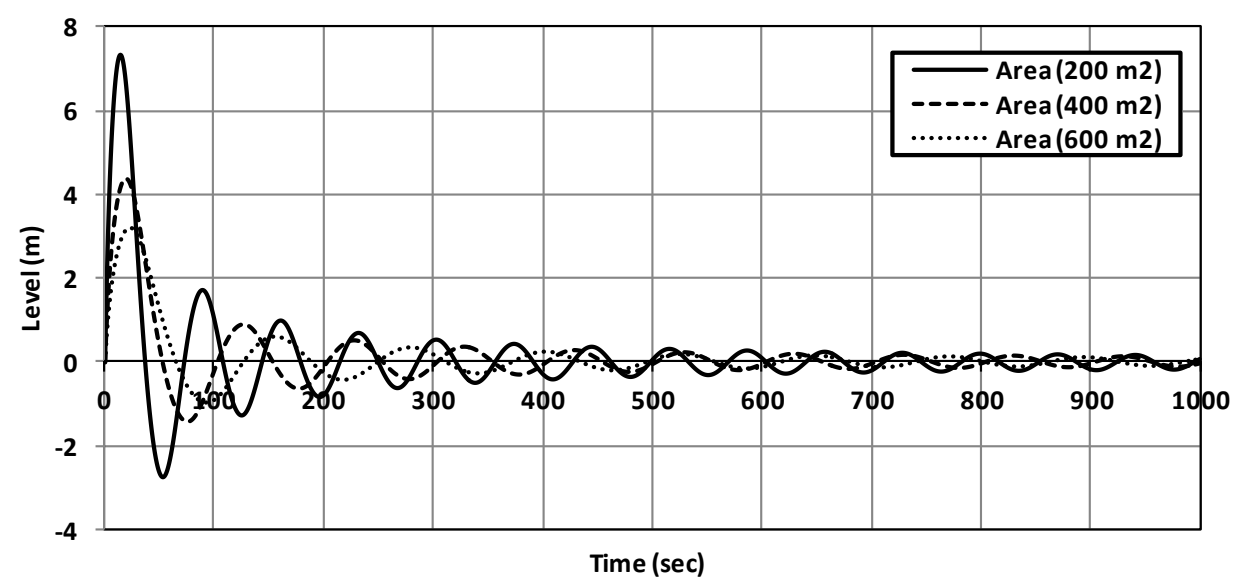

الشكل (3): تغير مستوى الماء في الخزان مع الزمن m m

تأثير تغيير مساحه مقطع الخزان على معدل تصريف الماء :

الثكل (4) يوضح تأثير تغيير مساحة مقطع الخزان على معدل تصريف الماء، فزيادة مساحه مقطع الخزان ينخفض مستوى التذبذب في معدلات تصريف الماء الناتجة من التأثثر العابر(غير المستقر)، هذه التقلبات تتغير من حوالي(-75 م²/ثانية) كحد أدنى إلى حوالي (+40 م³ثانية) كحد أقصى عند مساحه مقطع 200 م² ، ومن حوالي(-55 م م/ثانية ) كحد أدنى إلى (+25 م²ثانيـة) كحد أعلى عند مساحه 600 (2²)، وهذا يعني أن زيادة مساحه مقطع الخزان تعطي فرصه للتقليل من معدلات تصريف المياه مع انخفاض سرعه الموجه العابرة. 


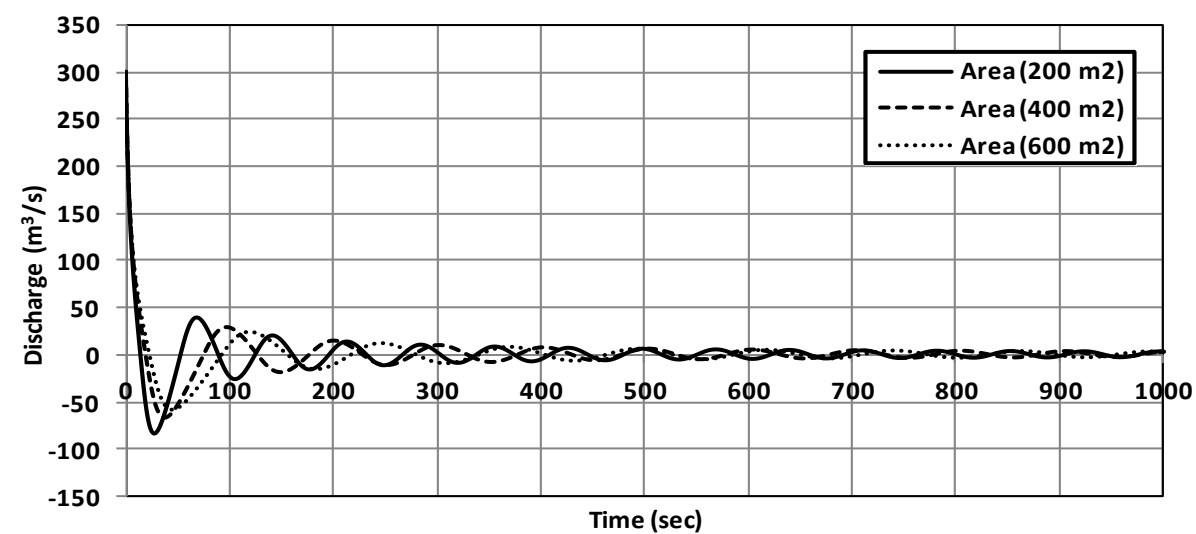

الثكل(4): تغير معدل التصريف مع الزمن (As=200,400,600 m²)

تأثير تغيير معامل الاحتكاك على مستوى الماء في الخزان:

تأثير تغيير معامل الاحتكالك على مستوى الماء في الخزان تم توضيحه عن طريق الثكل (5)، حيث من الواضح إنه بزباده معامل الاحتكاك ينخفض مستوى الماء في الخزان، وهذا راجع إلى أنه مع زيادة معامل الاحتكالك تزداد المقاومة لسريان الماء وتتخفض سرعته، وهذ ناتج عن إجهادات القص العالية التي تحدث بين جدار الأنبوب والماء الذى يسرى فيه. من خلال النتائج فإن مستوى الاندفاع المفاجئ للماء بـالخزان ينخفض من حوالي 17 متر عندما يكون معامل الاحتكالك (C=0) إلى حوالي 7.5 متر، عندما يكون معامـل الاحتكـاك (C=0.0004)، ويمكن ملاحظـة أنـه عند معامـل الاحتكـاك (C=0) كلما كان الأنبوب المستخدم في المحطات الكهرومائية خشنا كلما ساعد ذلك على التقليل من مشكلة مطرقة الماء وتخفيض حجم الخزان. 


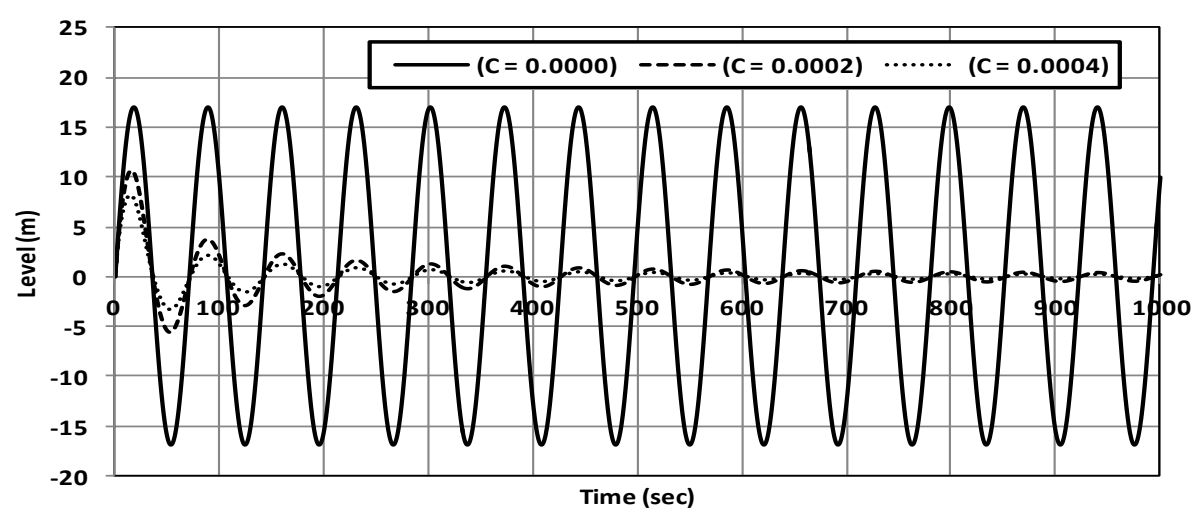

الثكل (5): تغير مستوى الماء في الخزان مع الزمن عذ (C= 0.0, 0.0002, 0.0004)

تأثير تغيير مساحة مقطع الخزان ومعامل الاحتكاك على مستوى الاندفاع الأول : من خلال النتائج السابقة فإن مستوى الاندفاع الأول للماء بالخزان يعد من أهم المتغيرات التي يجب

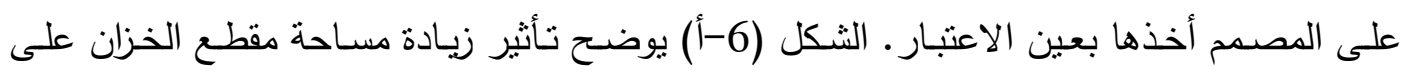
مستوى الاندفاع الأول بالخزان كما هو منوقع فإنه بزيادة مساحة مقطع الخزان يقل مستوى الاندفاع

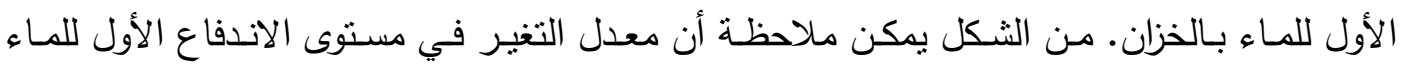
بالخزان بعد قيمة (A غير المجدي زيادة مساحة مقطع الخزان أكثر من هذه القيمة. وبالأسلوب نفسه فإن الثكل (6-ب) يوضح تأثير زيادة معامل الاحتكالك على مسنوى الاندفاع الأول للماء بالخزان، حيث إنه بزيادة معامل الاحتكالك يقل مستوى الاندفاع الأول للماء بالخزان بشكل ملحوظ. ويمكن ملاحظة أيضا أنه بزيادة معامل الاحتكاك عن القيمة (C=0.003) لن يكون مجديا، حيث إن التغير في مسنوى الاندفاع الأول للماء بالخزان لن يكون كبيرا. والجدير بالذكر أن هذا المتغير (معامل الاحتكاك) من الصعب التحكم

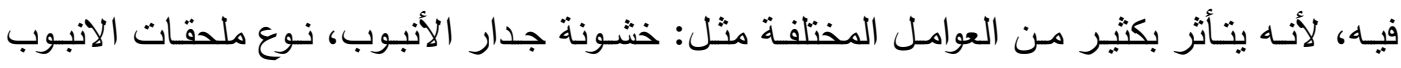
المستخدمة، طوبوغرافيا المكان، أبعاد خط الأنابيب، الموقع، فترة التشغيل، نمو الطحالب، الثوائب والرواسب، خواص السائل ...الخ. 


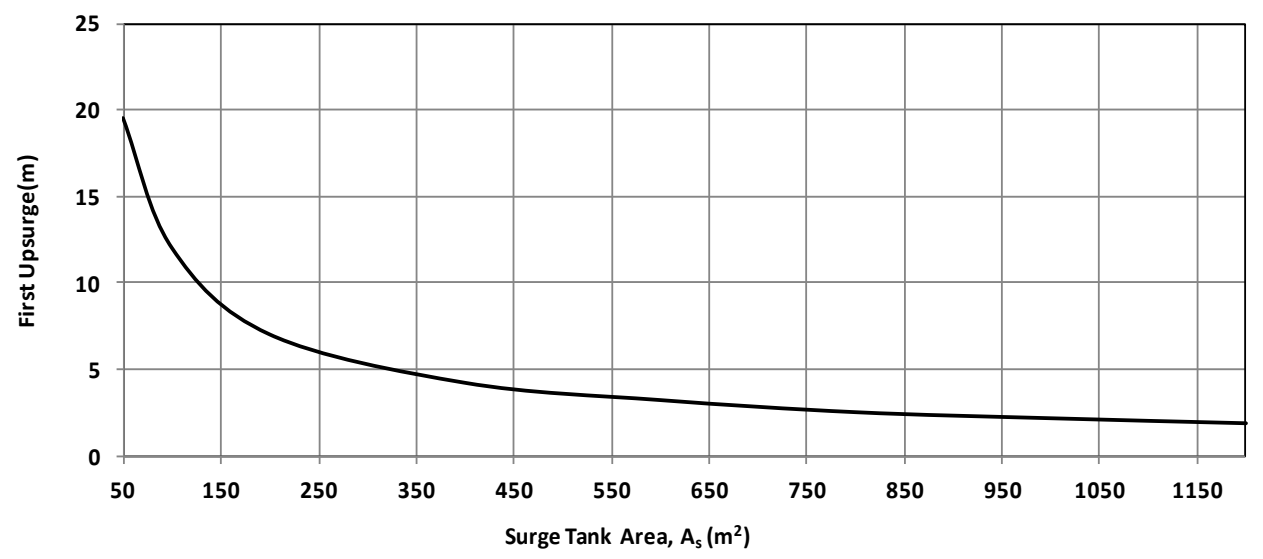

الثكل (6-أ): تغير مستوى الاندفاع الأول مع مساحة مقطع الخزان.

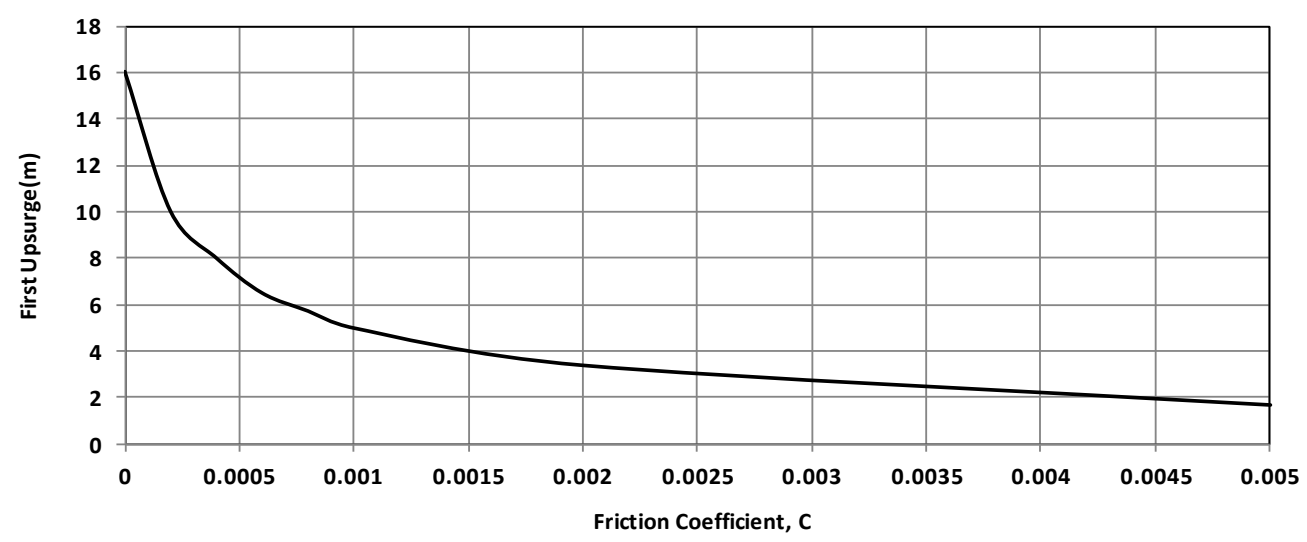

الشكل (6-ب): تغير مستوى الاندفاع الأول مع معامل الاحتكاك

الخزان ذو القتحة

تأثير تغيير مساحة مقطع الخزان على مستوى الماء في الخزان:

في الثكل (7)، تم توضيح تأثنر تغيير مسـاحه مقطع الخزان ذي الفتحـة على مستوى المـاء في الخـزان، مـن الواضــح أنـه إذا زادت مسـاحه مقطـع الخـزان انخفض مسـتوى المـاء فيـه، أي أن هنـالك تتاسبا عكسيا بينهما، ومن خلال الثكل المبين أدناه، يمكن ملاحظه أن مستوى الاندفاع الأول في الخزان ينخفض من 0.36 منر عند مساحه مقطع 200 (2²) إلى حوالي 0.0125 منر عند مساحه مقطع 600 (م²). والجدير بالماحظة أن مستوى الاندفاع المفاجئ في الخزان ذي الفتحة أقل بكثير من متله في الخزان البسيط وهذا راجع إلى تأثير الفتحة حيث إن الفقد في عمود الضغط والناتج عن 
تأثثير معامل الاحتكاك للفتحة (Corf) يكون كبيرا وملحوظاً عند المقارنة مـع الخزان البسيط، بالإضـافة إلى أن زمن تخميد الموجة في الخزان ذي الفتحة أقل بكثير من نظيره بالخزان البسيط.

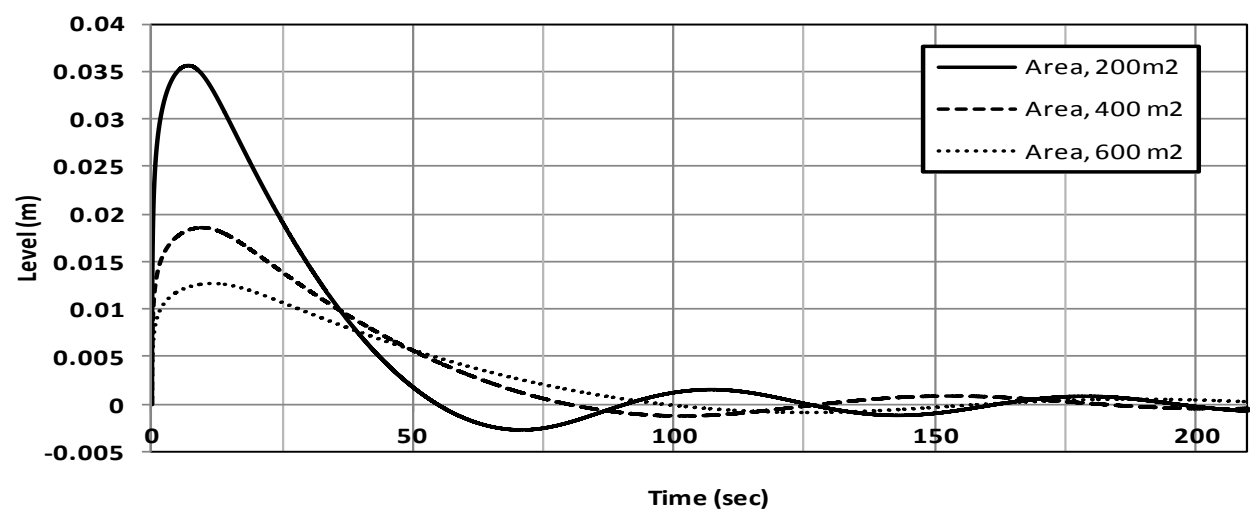

الشكل(7): تغير مستوى الماء في الخزان ذو الفتحة مع الزمن.

تأثير تغير معامل الاحتكاك على مستوى الماء في الخزان :

تأثير تغيير معامل الاحتكالك على مستوى الماء في الخزان ذي الفتحة تم توضيحه في الثكل (8)، من الواضح أنه بزيادة معامل الاحتكالك ينخفض مستوى الماء في الخزان وذلك لأنه مـ زياده معامل الاحتكاك تزبد مقاومـه الماء وتنخفض سرعته نتيجة لإجهادات القص العالية التي تحدث بين جدار الأنبوب والمـاء الذى يسري فيه، ومن خـلال النتائج فإن مستوى المـاء بـالخزان ينخفض من حوالي 0.17 متر عندما يكون معامـل الاحتكـاك (C=0) إلى حوالي 0.041 متر عندما يكون معامـل الاحتكالك (C=0.2)، ومن هنا يمكن ملاحظه التأثنر الإيجابي لزيادة معامل الاحتكاك للأنبوب والذي يساعد على تقليل وتخفيض التذبذبات والتقلبات في مستوى الماء بالخزان. 


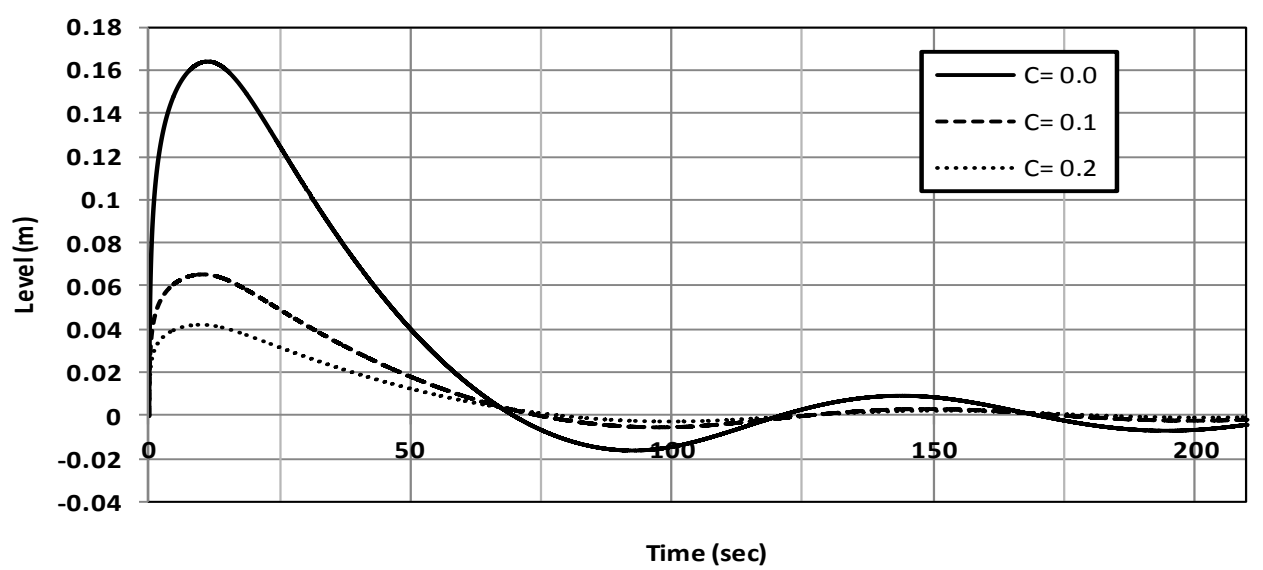

شكل (8): تغير مستوى الماء في الخزان مع الزمن عند (C= $0.0,0.1$ \& 0.1 (C)

\section{تأثير تغير معامل الاحتكاك على معدل التصريف :}

في الثكل (9) تم توضيح تأثير تغير معامل الاحتكالك على معدل التصريف. حيت يتضـح أنه بزياده معامل الاحتكاك تنخفض التذبذبات والتقلبات في معدلات التصريف الناتجة عن التأثنر العابر (غير المستقر) • هذا يعزى إلى زياده إجهادات القص بين جدار الأنبوب والماء الذي يسرى فيه مع زياده معامل الاحتكاك ـ وهذا واضـح من خـلال الأشكال المبينة حيت تنخفض معدلات التصريف بشكل سريع كلما زاد معامل الاحتكالك.

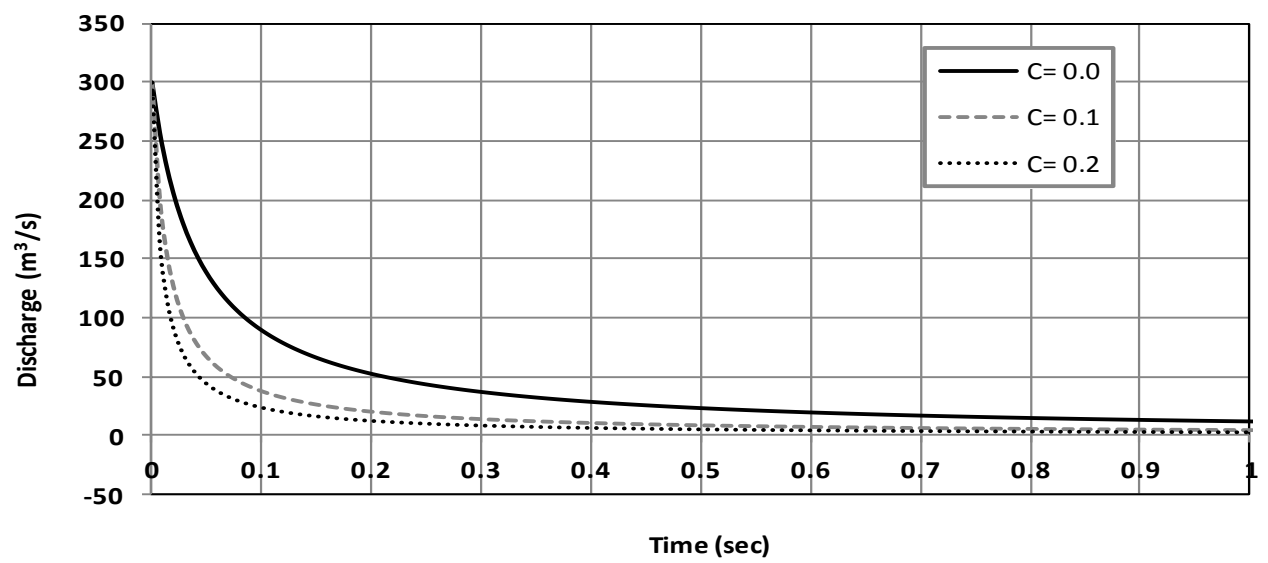

الثكل (9): تغير معدل التصريف مع الزمن. 
تأثير تغيير مساحة مقطع الحزان، معامل الاحتكاك للفتحة Corf ومعامل الاحتكاك C، على مستوى الاندفاع الأول للماء في الخزان ذي القتحة :

الثـكل (10-1أ) يوضـح تـأثير زيـادة مسـاحة مقطـع الخزان ذي الفتحـة على مسـتوى الاندفاع الأول بالخزان. كما هو متوقع فإنه بزيادة مساحة مقطع الخزان يقل مستوى الاندفاع الأول للماء بالخزان. من As= m²) الثكل يمكن ملاحظة أن معدل التغير في مستوى الاندفاع الأول للماء بالخزان بعد قيمة 400)، يكون بسيطاً عند مقارنته بنظيره قبل هذه القيمة، لهذا فإنه من غير المجدي زبادة مساحة مقطع الخزان أكثر من هذه القيمة. و بالأسلوب نفسه فإن الثكل (10-ب) يوضح تأثنر زيادة معامل الاحتكالك للفتحة على مستوى الاندفاع الأول للماء بالخزان، حيث إنه بزيادة معامل الاحتكاك للفتحة، فإن مستوى الاندفاع الأول للماء بالخزان يقل بشكل ملحوظ. ويمكن ملاحظة أيضـاً أنه بزيادة معامل الاحتكالك للفتحة عن القيمة (Corf للماء بالخزان لن يكون كبيراً. الثكل (10-ج) يوضح تأثثير زيادة معامل الاحتكاك على مستوى الاندفاع الأول للماء بالخزان، حيث إنه بزيادة معامل الاحتكالك يقل مستوى الاندفاع الأول للماء بالخزان بشكل ملحوظ ، ويمكن ملاحظة أيضا أنه بزيادة معامل الاحتكاك عن القيمة (C=0.2) لن يكون مجدياً، حيث إن التغير في مستوى

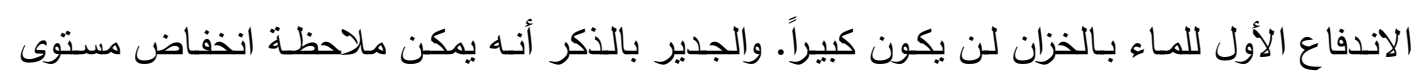
الاندفاع الأول بشكل عام في الخزان ذي الفتحة عند مقارنته بنظيره في الخزان البسيط.

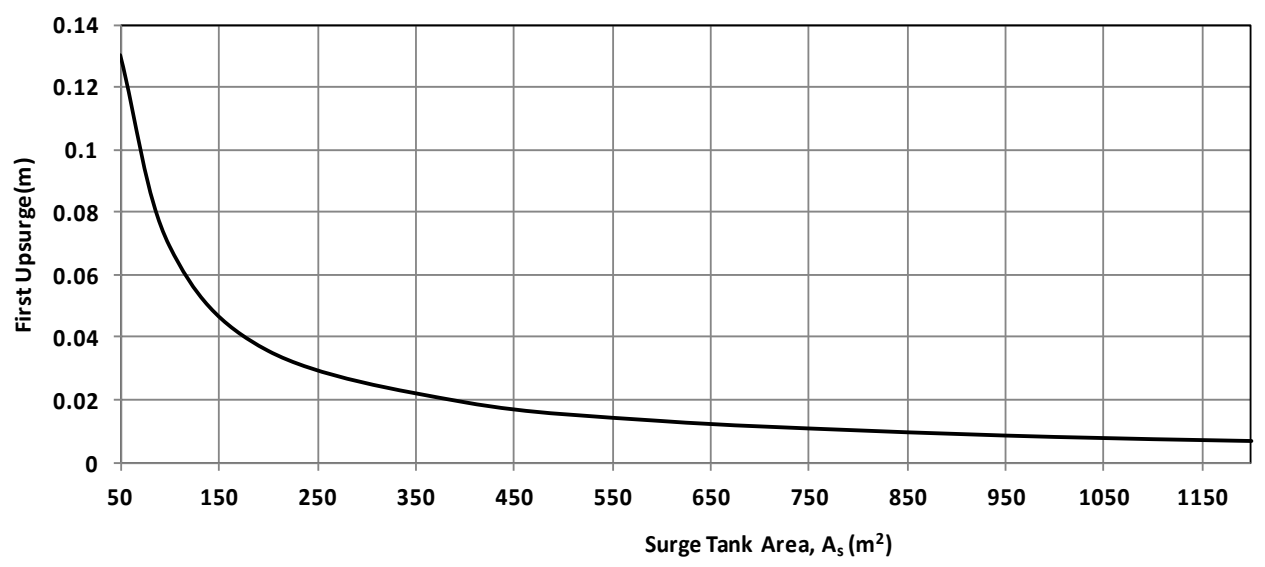

الثكل (10-أ): تغير مستوى الاندفاع الأول مع مساحة مقطع الخزان. 


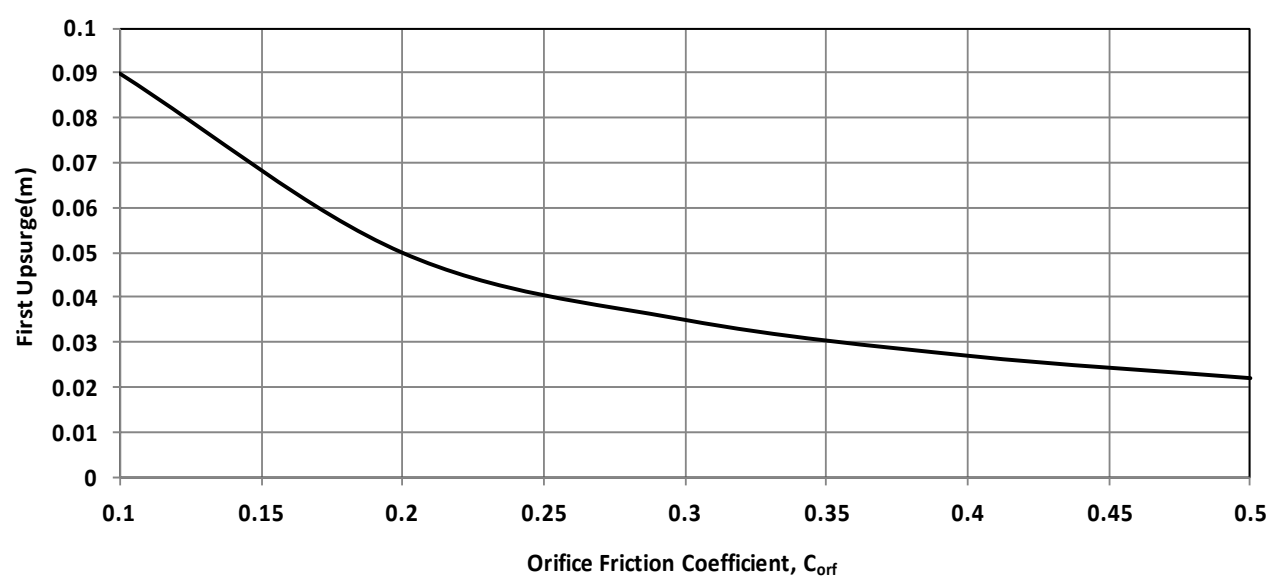

الثكل (10-ب): تغير مستوى الاندفاع الأول مع معامل الاحتكات للفتحة.

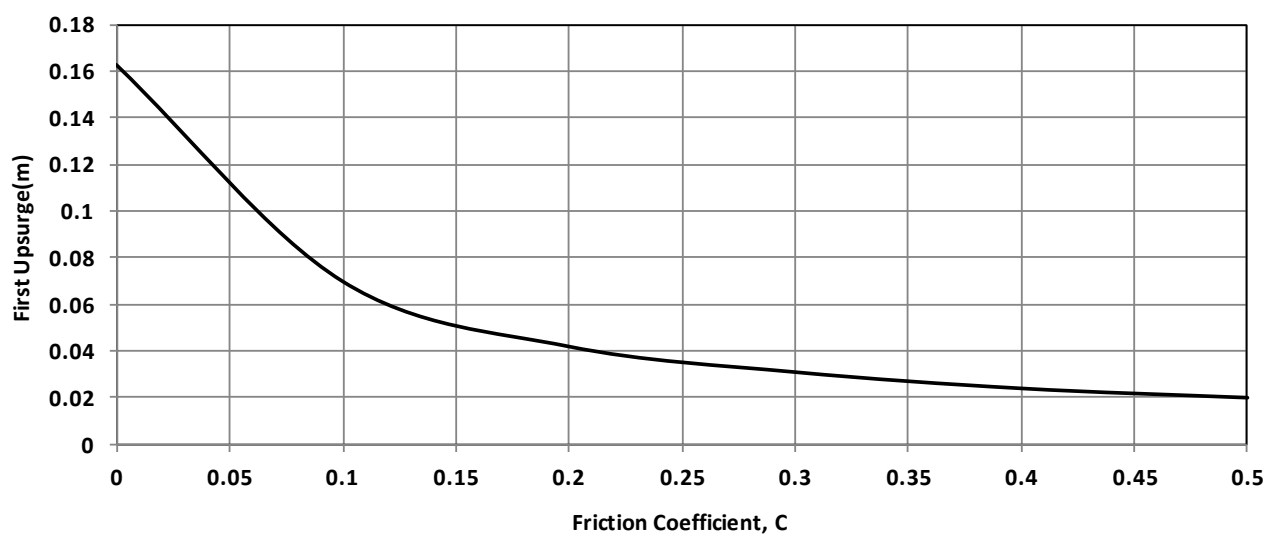

الشكل (10-ج): تغير مستوى الاندفاع الأول مع معامل الاحتكاك.

في هذه الدراسة تم إجراء مقارنة بين بعض أنواع خزانات التموج المستخدمة في تخميد موجة الاندفاع المفاجئ للماء الناتجة عن مشكلة مطرقة الماء في المحطات الكهرومائية. تم تطبيق هذه الدراسـة على نوعين من أنواع خزانات التموج هـا الخزان البسيط والخزان ذو الفتحة. تم استخدام نموذج رياضـي مبني على أساس اثتقاق معادلة الاستمرارية ومعادلة كمية الحركة (الزحم)، وتطبيق المبادئ الأساسية لميكانيكا الموائع على الخزانين. تم حل المعادلات التفاضلية العادية الحاكمة عدديا باستخدام طريقة رانج-كوتا وبالاستعانة ببرامج الحاسب الآلي وفق الثروط الابتدائية والظروف التشغيلية، بهدف معرفة تأثير العوامل المختلفة مثل مساحة مقطع الخزان، معامل الاحتكالك لجدار الأنبوب ومعامل الاحتكالك 
للفتحة على مستوى الماء بالخزان، معدلات تصريف المياه وزمن تخميد الموجة. يمكن تلخيص أهم

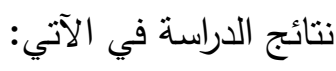

بشكل عام لوحظ أنه بزيادة ساحه مقطع خزان التموج انخفض مستوى الاندفاع المفاجئ للماء في

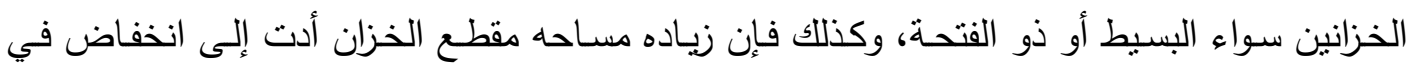
التقلبات والتذبذبات في معدلات تصريف المياه، وكذلك في الزمن اللازم لتخميد الموجه، مع ملاحظة الانخفاض الكبير في هذه المتغيرات في الخزان ذي الفتحة عند مقارنتها بنظيراتها في الخزان البسيط.

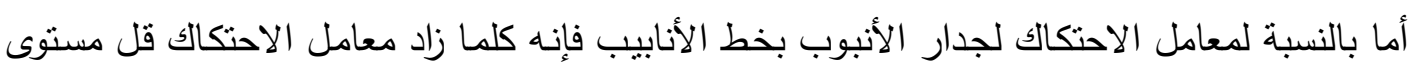

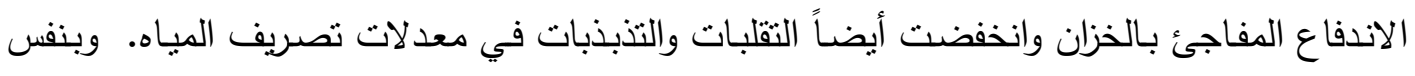

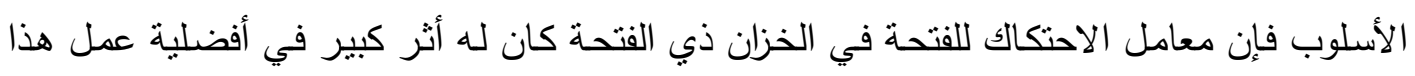

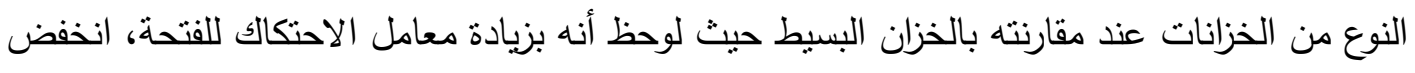

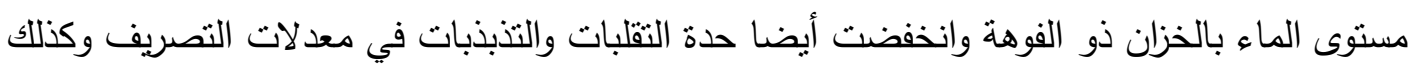
زمن تخميد الموجة. وممـا تقدم يمكن اعتبار أن الخزان ذا الفتحـة أفضل من الخزان البسيط، ويمكن استخدامه لحل مشكلة مطرقة الماء بعد الأخذ بعين الاعتبار أن القرار النهائي باستخدام هذه الخزانات

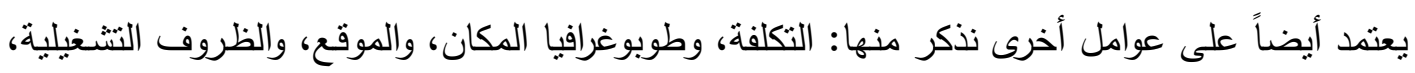
والمعدات والآلات المستخدمة، ومنطلبات الحمل على التربينه، والعمالة ...الخ.

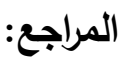

- Ramadan A.M \& Mustafa .H (2013)," Surge Tank Design Considerations for Controlling Water Hammer Effects at Hydroelectric Power Plants", University Bulletin - Issue No.15 - Vol . 3, pp 147-160.

- Ghulam N., Habib-ur-Rehman, Muhammad K. and Muhammad T. (2011)," Hydraulic Transient Analysis of Surge Tanks: Case Study of Satpara and Golen Gol Hydropower Projects in Pakistan", Pak. J. Engg. \& Appl. Sci. , Vol. 8, Jan., pp 34-48.

- Azhdary M. (2004), “Analysis and Design of a Simple Surge Tank”, IJE Transactions A:Basics, Vol. 17, No.4, pp 339-345.

- Verhoeven R., Van Poucke L. and Huygens M. (1998)," Water Hammer Protection with Air Vessels, a Comparative Study", Transactions on Engineering Sciences, Vol 18, pp 1743-3533. 
- Pinar B. (2013)," Numerical Investigation of Effective Surge tank Dimensions in Hydro-power Plants under various Hydraulic Conditions", Msc Thesis, METU.

- Urbanowicz K., Firkowski M. and Zarzycki Z (2016)," Modeling Water Hammer in Viscoelastic Pipelines: Short Brief", Journal of Physics: Conference Series 760, pp 1-11.

- Chaudhry M.H. (1987)," Applied Hydraulic Transients", Van Nostrand Reinhold, NewYork, $2^{\text {nd }}$ edition. 